8. McClellan M, McKethan A, Lewis J, Roski J, Fisher E. A national strategy to put accountable care into practice. Health Aff (Millwood). 2010;29(5):982-90. Available at: https://www.healthaffairs.org/doi/full/10.1377/hlthaff. 2010.0194. Accessed April 24, 2020.

9. Cranor CW, Bunting B, Christensen DB. The Asheville Project: long-term clinical and economic outcomes of a community pharmacy diabetes care program. J Am Pharm Assoc (Wash). 2003;43(2):173-84.

10. Anaya JP, Rivera JO, Lawson K, Garcia J, Luna Jr J, Ortiz M. Evaluation of pharmacist-managed diabetes mellitus under a collaborative drug therapy agreement. Am J Health Syst Pharm. 2008;65(19):1841-45.
11. Ni W, Colayco D, Hashimoto J, et al. Reduction of healthcare costs through a transitions-of-care program. Am J Health Syst Pharm. 2018;75(10):613-21.

12. Pellegrin KL, Krenk L, Jolson Oakes S, et al. Reductions in medicationrelated hospitalizations in older adults with medication management by hospital and community pharmacists: a quasi-experimental study. J Am Geriatr Soc. 2017;65(1):212-19.

13. Wright EA, Graham JH, Maeng D, et al. Reductions in 30-day readmission, mortality, and costs with inpatient-to-community pharmacist followup. J Am Pharm Assoc (2003). 2019;59(2):178-86.

14. Pharmacist eCare Plan Initiative. Available at: www.ecareplaninitiative.com. Accessed April 24, 2020.

\title{
Evolution of the Pharmacy Benefit Manager/Community Pharmacy Relationship: An Opportunity for Success
}

\author{
Patty Taddei-Allen, PharmD, MBA, BCACP, BCGP
}

\section{Taddei-Allen's Viewpoint}

$\mathrm{B}$ usiness commodities are any good or service that can be bought or sold based solely on price. These include typical commodities, such as agricultural products such as beans and rice and natural resources such as oil or gas. There is no difference in the brand, benefits, or distinguishing features when you buy rice from company A versus company B. Service product offerings can also become commodities when, in the eyes of the consumer, the service rendered is indistinguishable from others in terms of uniqueness or other attributes.

Unfortunately, the historical business model for community pharmacy has led to the commoditization of this important health care resource. The traditional community pharmacy business model of filling as many prescriptions as quickly and accurately as possible, and at lower and lower cost, has become unsustainable in our profession. If you take a survey of people's experiences with filling their prescriptions at one chain drug store versus another, or from one grocery store chain, big box store, or even an independent pharmacy, most people will respond that the service is pretty much the same. They may prefer a particular store because of the pharmacists and staff

J Manag Care Spec Pharm. 2020;26(6):708-10

Copyright $\odot 2020$, Academy of Managed Care Pharmacy. All rights reserved. who work there or because of the ease of being able to refill their prescriptions via an app, but the number one overwhelming reason why patients choose a drugstore is location. ${ }^{1}$

\section{Current Community Pharmacy Business Model}

Pharmacies enter contracts with pharmacy benefit managers (PBMs) to be part of a PBM network. The incentive for pharmacies to join networks, with predetermined rates for reimbursement for brand and generic products, as well as a dispensing fee, is to have access to a PBM's members who may go to their pharmacies to fill prescriptions. PBMs typically offer better rates for generics than brands in order to incentivize pharmacies to promote the use of generic products. Certain generics may also be managed by maximum allowable cost pricing, which limits the overall reimbursement for a particular medication based on the best cost available among different manufacturers, requiring the pharmacy to shop for the best-priced generic product from their wholesaler.

In 2012, the Centers for Medicare \& Medicaid Services released detailed data on pharmacy acquisition costs and pharmacy revenues, in essence making it possible to see how much profit pharmacies were making. An analysis of more than 3,200 drugs by Pembroke Consulting showed that the average gross profit per prescription was $\$ 7.46$. This is, however, a blended average gross profit, where about $5 \%$ of the drugs had 
negative gross profits, while 5\% had gross profits above $\$ 20$ per prescription. In general, brand products had a higher gross profit than generic products. ${ }^{2}$

The shift in the increase of generic drugs dispensed over the last 10-15 years has had an effect on how pharmacies are able to profit. Pharmacies in the past tended to make higher profits with less dispenses because of a lower amount of generic drugs available than today, since brand gross profit was higher than generics. The focus today on more dispenses is in part because there is less profit margin per total prescription filled due to the increase in proportion of generic prescriptions, and pharmacies must make up the difference in volume to meet financial objectives. The current drug pipeline is negligible with nonspecialty drugs compared with specialty drugs, and more patent expirations are on the horizon, steering generic dispensing even higher. In addition, some PBMs charge retroactive fees that further shrink margins.

Pharmacies that have extensive automation and are able to fill vast amounts of prescriptions will have the financial advantage in the service of dispensing medications. They can take advantage of economies of scale, dramatically driving down the cost per fill compared with any community pharmacy. It is estimated that online and mail order pharmacy use will increase, particularly with the improvements in technology and consumers' desire for home delivery.

\section{Looming Primary Care Provider Shortage}

The Association of American Medical Colleges estimates a looming shortage of between 21,100 and 55,200 primary care physicians by 2032 . The pace at which primary care providers are needed is augmented by several factors, including the aging baby boomer generation and the overall increasing incidences of diabetes and obesity, linked with several other comorbid chronic conditions. ${ }^{3}$

In 2018, PrescribeWellness surveyed over 1,000 U.S. adults over age 40 and found that older Americans would like to have more health services offered at their local community pharmacy. Over $46 \%$ of respondents were willing to pay cash for preventive health services at their pharmacy instead of a copayment at a doctor's office, and over half said they would transfer their prescriptions to a pharmacy that provided other preventive care services. Other top pharmacy health services include immunizations, flu or strep point-of-care testing, and blood pressure checks. The survey also found that older Americans already have a high degree of trust in their community pharmacists and seek them in order to help manage their medications. ${ }^{4}$

\section{Dismal Job Outlook}

According to the U.S. Bureau of Labor Statistics, there were over 314,000 total pharmacist jobs in 2018, with an outlook of virtually no change over the next 10 years. ${ }^{5}$ Combining this with the large amount of pharmacy students graduating every year has resulted in an overabundance of pharmacists in the workforce. The U.S. Bureau of Labor Statistics projects that while there will be increases in pharmacist jobs in hospitals and clinics, the amount of positions with drug stores will decline. However, one may argue that this projection is based on the assumption that the current model of community pharmacy will continue to be focused primarily on dispensing. The U.S. Bureau of Labor Statistics lists roles for expanding pharmacist positions related to overseeing patients' medications and providing direct patient care, such as checking blood pressure, blood sugar, or cholesterol. What prevents these tasks from being managed and completed by community pharmacists?

\section{Future of Community Pharmacy}

Over $80 \%$ of Americans receive some sort of prescription benefit through a PBM. Three large PBMs make up almost 78\% of overall market share, leaving all other PBMs fighting for a slice of the pie. The larger a PBM is the better they are able to compete with regards to price. As a result, mid-market PBMs must compete on other value-adds, such as clinical and trend management.

PBMs should be interested in community pharmacies that offer these additional clinical services to their members and see them as partners helping them achieve both clinical and trend management. However, these collaborations should be based on incentives, not on collecting retroactive fees. Models where pharmacies that may be credentialed by a PBM or are able to demonstrate achievement of some agreed-upon clinical metric and receive a higher dispensing fee for a particular class of medications should be explored.

One of the biggest trend drivers in the nonspecialty disease states is diabetes. Diabetes is a difficult disease to treat and requires a multimodal approach, with the patient in the center, to help achieve optimal clinical and financial outcomes. A possible model would be that a specific pharmacy has the incentive to provide ongoing lifestyle counseling to patients with diabetes, confirm that medication regimens are following clinical treatment guidelines, and ensure that gaps in care are addressed and closed for the diabetic patients. This can result in a win-win-win-win scenario-the patient receives optimal care; the pharmacy is reimbursed for its clinical expertise; the PBM is able to manage spend and trend; and the plan sponsor has lower overall health care costs with a better managed diabetes population.

Pharmacists are trained to deliver patient-centered care, and many seek out additional certifications to improve their delivery of health care. Pharmacy school curricula has changed, particularly in the last 10 years, to be more patient-centered and collaborative with other providers. Pharmacists are poised to be key players in helping to manage chronic disease-state patients. Across the United States, community pharmacies, 
including independent pharmacies, that want to survive in the face of daunting retail challenges need to create different valueadds to their service offerings. The market is there-patients like going to their pharmacies, trust their pharmacists, and will have (if not already) a need for access to primary care. The training, skills, education, and, most importantly, the pharmacists' desire to help patients is there.

\section{Conclusions}

These elements-the changing economic landscape, the patient perception of filling a prescription as a commodity, the looming primary care provider shortage, and the clinical expertise that pharmacists possess-are working together to push for a paradigm shift in how community pharmacists practice pharmacy. Community pharmacists need to practice at the height of their licensure, with less focus on order fulfillment and more focus on improving patient care.

\section{Authors}

PATTY TADDEI-ALLEN, PharmD, MBA, BCACP, BCGP, Senior Director, Clinical Analytics, WellDyne, Lakeland, Florida.

AUTHOR CORRESPONDENCE: Patty Taddei-Allen, PharmD, MBA, BCACP, BCGP, Senior Director, Clinical Analytics, WellDyne, 500 Eagles Landing Dr., Lakeland, FL 33810. Tel.: 863.583.6085;

E-mail:ptaddei-allen@welldyne.com.

\section{DISCLOSURES}

No funding supported the writing of this commentary. The author has nothing to disclose.

\section{REFERENCES}

1. Eder R. How consumers choose a pharmacy. Drug Store News. April 16 2012. Available at: https://drugstorenews.com/pharmacy/how-consumerschoose-primary-pharmacy. Accessed April 27, 2020.

2. Fein A. Transparency is here! CMS exposes pharmacy prescription profit margins. Drug Channels Institute. October 9, 2012. Available at: https:// www.drugchannels.net/2012/10/transparency-is-here-cms-exposes.html. Accessed April 27, 2020.

3. Association of American Medical Colleges. New findings confirm predictions on physician shortage. April 23, 2019. Available at: https://www.aamc. org/news-insights/press-releases/new-findings-confirm-predictions-physician-shortage. Accessed April 27, 2020.

4. Chain Drug Review. Patients want pharmacies to go 'beyond the fill'. January 22, 2018. Available at: https://www.chaindrugreview.com/patientswant-pharmacies-to-go-beyond-the-fill/. Accessed April 27, 2020.

5. U.S. Bureau of Labor Statistics. Occupational Outlook Handbook. Pharmacists. September 4, 2019. Available at: https://www.bls.gov/ooh/ healthcare/pharmacists.htm\#tab-1. Accessed April 27, 2020.

\title{
Employer and Plan Sponsor Views on Pharmacy Reimbursement
}

\author{
Michael Stull, MBA, and Cristy Gupton
}

\section{Stull \& Gupton's Viewpoint}

$\mathrm{F}$ or decades, employers and plan sponsors have sought to quantify the outcomes achieved for the dollars spent on health care products and services for plan participants. To date, we have

J Manag Care Spec Pharm. 2020;26(6):710-12

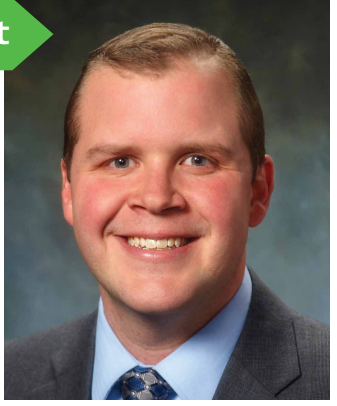

Copyright $\odot 2020$, Academy of Managed Care Pharmacy. All rights reserved.

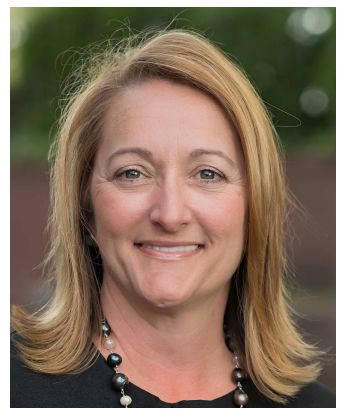

seen some progress towards this aim by progressive plan sponsors and government payers on the medical side, rewarding doctors and hospitals for achieving specific quality outcomes and cutting reimbursement and/or access to lower value providers. Still, there is ample opportunity to expand these efforts, improve results, and accelerate the uptake of outcomes-based or valuebased purchasing strategies by employers. 